\title{
Mikolojik Tanının Önemi: 20 Yıl İhmal Edilen Bir Scedosporium apiospermum Kompleks Miçetoma Olgusu
}

\section{The Importance of Mycological Diagnosis: A Scedosporium apiospermum Complex Mycetoma Case Neglected For 20 Years}

\author{
Ayşe BARIŞ ${ }^{1}(I D)$, Ahsen ÖNCÜL ${ }^{2}(I D)$, Kahraman ÖZTÜRK ${ }^{3}(I D)$, Alican BARIŞ ${ }^{4}(I D)$, \\ Serkan $\operatorname{AYKUT}^{3}(I D)$, Elif AKTAŞ ${ }^{1}$ (ID) \\ 1 Sağlık Bilimleri Üniversitesi, Şişli Hamidiye Etfal Eğitim ve Araştırma Hastanesi, Tıbbi Mikrobiyoloji Laboratuvarı, İstanbul. \\ ${ }^{1}$ University of Health Sciences, Sisli Hamidiye Etfal Research and Training Hospital, Department of Medical Microbiology, \\ Istanbul, Turkey. \\ 2 Şişli Hamidiye Etfal Eğitim ve Araştırma Hastanesi, Enfeksiyon Hastalıkları ve Klinik Mikrobiyoloji, İstanbul. \\ 2 University of Health Sciences, Sisli Hamidiye Etfal Research and Training Hospital, Department of Infectious Diseases and \\ Clinical Microbiology, Istanbul, Turkey. \\ ${ }^{3}$ Sağlık Bilimleri Üniversitesi, Metin Sabancı Baltalimanı Kemik Hastalıkları Eğitim Araştırma Hastanesi, \\ Ortopedi ve Travmatoloji Kliniği, İstanbul. \\ ${ }^{3}$ University of Health Sciences, Metin Sabancı Baltalimanı Bone Diseases Training and Research Hospital, Department of \\ Orthopedics and Traumatology, Istanbul, Turkey. \\ ${ }^{4}$ Sağlık Bilimleri Üniversitesi, İstanbul Eğitim ve Araştırma Hastanesi, Ortopedi ve Travmatoloji Kliniği, İstanbul. \\ ${ }^{4}$ University of Health Sciences, Istanbul Training and Research Hospital, Department of Orthopedics and Traumatology, \\ Istanbul, Turkey.
}

\footnotetext{
* Bu olgu, 13. Antimikrobik Kemoterapi Günleri (Acıbadem Mehmet Ali Aydınlar Üniversitesi, ìstanbul 6 - 8 Nisan 2018)'nde sözlü bildiri olarak sunulmuştur.
}

Makale Atıfı: Barış A, Öncül A, Öztürk K, Barış A, Aykut S, Aktaş E. Mikolojik tanının önemi: 20 yıl ihmal edilen bir Scedosporium apiospermum kompleks miçetoma olgusu. Mikrobiyol Bul 2021;55(2):256-264.

\section{ÖZ}

Scedosporium apiospermum kompleks üyeleri toprak ve kirli sular gibi çevresel ortamlarda bulunabilen fırsatçı mantarlardır. Bu raporda, 40 yaşında immün sistemi sağlam kadın hastada gelişen ve mantar kültürü yapılmasıyla tanı alabilen Scedosporium apiospermum kompleks kaynaklı miçetoma olgusu sunulmuştur. 2015 yılında sağ el ve el bileği dorsalinde birden fazla fistülize akıntılı yara, ağı ve şişlik şikayeti ile başvuran hastanın anamnezinde, şikayetlerinin yaklaşık 20 yıl önce el bileği sırtında hafif bir şişlik ile başladığı ve artması üzerine özel bir cerrahi merkezinde apsenin drene edilerek antibiyotik tedavisine başlandığı öğrenilmiştir. Ancak tedavilerden fayda görmediği, zamanla el ve el bileği sırtında fistülize sarı akıntılı yaralar çıktığı ve çeşitli cerrahi müdahaleler geçirip antibiyotik kullandığı öğrenilmiştir. Altta yatan kronik bir hastalığı olmayan hastanın rutin laboratuvar tetkikleri normal olarak saptanmıştır. Manyetik rezonans görüntüleme (MRG) ve X-ray bulguları osteomyelit ile uyumlu ve MRG'de miçetoma için karakteristik olan "dot in circle (çember içinde nokta)" bulgusu olduğu görülmüştür. Patolojik inceleme yumuşak dokuda aktif kronik iltihabi reaksiyon, kronik osteomyelit şeklinde yorumlanmıştır. Cerrahi debridman esnasında ve bir ay sonra tekrar alınan her iki biyopsi örneğinin mikobakteri, bakteriyoloji ve mantar kültürleri 
yapılmıştır. Bakteriyoloji ve mikobakteri kültürlerinde üreme olmamış ve her iki örneğin mantar kültüründe Scedosporium cinsi mantar üremiştir. İzolatlar; MALDI Biotyper (Bruker Daltonics, Bremen, Almanya) sistemiyle Scedosporium apiospermum/Pseudallescheria boydii) ve ITS bölgesinin dizi analizi ile Scedosporium boydii olarak tanımlanmıştır. Antifungal duyarııık testleri CLSI M38-A2 kriterlerine göre uygulanmış ve 72. saatte değerlendirilmiştir. Antifungallerin minimum inhibitör konsantrasyon (MiK) değerleri flukonazol, kaspofungin, amfoterisin B, itrakonazol, vorikonazol, posakonazol, isavukonazol için sırasıyla $>64 \mu \mathrm{g} /$ $\mathrm{ml}, 16 \mu \mathrm{g} / \mathrm{ml}, 4 \mu \mathrm{g} / \mathrm{ml}, 16 \mu \mathrm{g} / \mathrm{ml}, 0.25 \mu \mathrm{g} / \mathrm{ml}, 2 \mu \mathrm{g} / \mathrm{ml}$ ve $0.25 \mu \mathrm{g} / \mathrm{ml}$ olarak belirlenmiştir. Hastaya vorikonazol ve terbinafin tedavisi başlanmışır. Tedavinin dokuzuncu ayında yapılan muayenesinde akıntı, ağı ve şişlik şikayetlerinin geçtiği, fistül ağızlarının kapandığı ve eklem hareketlerinin ağrısız olduğu gözlenmiştir. 15 ve 18. ayında yapılan kontrol MRG'de yumuşak doku tutulumunun olmadığı, bulguların enfektif osteomyelit sonrası osteoartrit ile uyumlu olduğu görülmüştür. Uzun süreli şikayetleri mikolojik tanı ve uygun tedavi ile düzelmiş olan bu olgu, kronik kemik ve yumuşak doku enfeksiyonlarında mikolojik tanının akla getirilmesinin önemini ortaya koymaktadır. Mantarın cins ve tür düzeyinde tanımlanması ve tedavinin antifungal duyarlılık test sonuçlarına göre düzenlenmesi hasta yönetiminde oldukça önemlidir.

Anahtar kelimeler: Scedosporium apiospermum kompleks; Scedosporium boydii; miç̧etoma; mantar kültürü; antifungal duyarlılk testi.

\section{ABSTRACT}

Scedosporium apiospermum complex members are opportunistic fungi that can be found in environments such as soil and polluted water. In this report, we aimed to present a case of mycetoma caused by Scedosporium apiospermum complex that developed in a 40-year-old female patient with immunocompetent system and diagnosed by fungal culture. In the anamnesis of the patient who admitted in 2015 with the complaint of more than one fistulized discharge wound, pain and swelling in the dorsal of the right hand and wrist; it was learned that her complaints started about 20 years ago with a slight swelling on the back of the wrist, and when it worsened, the abscess was drained and antibiotic treatment was initiated in a private surgical center. However, it was learned that she did not benefit from the treatments, and over time, fistulized, yellow-discharged wounds appeared on the back of her hand and wrist, and she had undergone various surgical interventions and used antibiotics. Routine laboratory tests of the patient, who did not have an underlying chronic disease, were normal. Magnetic resonance imaging (MRI) and X-ray findings were compatible with osteomyelitis and 'dot in circle' sign seen on MRI was characteristic for mycetoma. Pathological examination was interpreted as active chronic inflammatory reaction in the soft tissue and chronic osteomyelitis. Mycobacteria, bacteriological and fungal cultures of the two biopsy samples taken during surgical debridement and one month later were performed. Bacteriological and mycobacterial cultures were negative, while Scedosporium genus grew in the fungal cultures of the both samples. Isolates were identified as Scedosporium apiospermum/Pseudallescheria boydii with MALDI Biotyper (Bruker Daltonics, Bremen, Germany) system and Scedosporium boydi by sequence analysis of the ITS region. The antifungal susceptibility tests were performed according to CLSI M38-A2 criteria, and were evaluated at the $72^{\text {nd }}$ hour. The minimum inhibitory concentration (MIC) values of fluconazole, caspofungin, amphotericin B, itraconazole, vorikonazole, posaconazole and isavuconazole were $>64 \mu \mathrm{g} / \mathrm{ml}, 16 \mu \mathrm{g} / \mathrm{ml}, 4 \mu \mathrm{g} / \mathrm{ml}, 16 \mu \mathrm{g} / \mathrm{ml}, 0.25 \mu \mathrm{g} / \mathrm{ml}, 2 \mu \mathrm{g} / \mathrm{ml}$ and $0.25 \mu \mathrm{g} / \mathrm{ml}$, respectively. Voriconazole and terbinafine treatment was initiated. In the control performed in the $9^{\text {th }}$ month of the treatment, it was observed that the complaints of discharge, pain and swelling were resolved, pain and swelling complaints were recovered, fistula tracts were closed and joint movements were painless. In the control MRI performed at $15^{\text {th }}$ and $18^{\text {th }}$ months, it was observed that there was no soft tissue involvement and the findings were compatible with osteoarthritis after infective osteomyelitis. This case whose longterm complaints improved with mycological diagnosis and appropriate treatment; reveals the importance of keeping mycological diagnosis in mind in chronic bone and soft tissue infections. Identifying the fungus to the genus and species level and arranging the treatment according to the antifungal susceptibility test results are very important in patient management.

Keywords: Scedosporium apiospermum kompleks; Scedosporium boydii; mycetoma; fungal culture; antifungal susceptibility test. 


\section{Gíriş}

Miçetoma; cilt, subkutan doku ve kemiği etkileyebilen kronik granülomatöz bir hastalıktır. Filamentöz basiller (aktinomiçetoma) veya mantarlardan (miçetoma) kaynaklanabilir. Genellikle travma sonrası gelişir. Vücudun farklı bölgelerinde görülebilmesine karşın en sık ayak ve el etkilenir ${ }^{1,2}$. Miçetoma tropikal ve subtropikal bölgelerde endemiktir. Özgül olmayan klinik özellikleri nedeniyle endemik olmayan bölgelerde yanlış tanı konulabilmekte ya da tanı gecikebilmektedir ${ }^{3}$. Miçetomanın önemli etkenlerinden biri Scedosporium apiospermum komplekstir ${ }^{4}$. Ascomycota şubesinde, Microascaceae takımında yer alan S.apiospermum kompleks içinde insanda enfeksiyonlardan sorumlu olan türlerden klinikle sık ilişkili olan S.apiospermum, S.boydii ve S.aurantiacum ve yaygın olmayan S.minutispora ve S.dehoogii yer almaktadır. Scedosporium türleri çevresel alanlarda organik atıkların zengin olarak bulunduğu toprak ve kirli sularda bulunur ancak insanların çevreye olan etkisiyle kentsel alanlarda da kolonizasyonu artmaktadır ${ }^{5,6}$. Scedosporium türleri, immün sistemi baskılanmış kişilerde hayatı tehdit eden fırsatçı enfeksiyonlar oluştururken immün sistemi sağlam bireylerde en sık travma ile ilişkili lokal enfeksiyonlara (miçetoma vb.) neden olmaktadır ${ }^{4}$. Aspergillus dışı küf mantarlarının neden olduğu invaziv enfeksiyonlarda sık görülen mantarlar arasında yer almaktadır ${ }^{7}$. Scedosporium türlerinde antifungallere karşı görülen intrinsik direnç/yüksek minimum inhibitör konsantrasyon değerleri ve sistemik enfeksiyonlardaki yüksek mortalite oranları nedeniyle enfeksiyonların yönetimi oldukça zordur $^{4}$. Bu nedenle tür tanımının doğru yapılması, antifungal duyarlılığın belirlenmesi ve uygun tedavinin düzenlenmesi önem taşımaktadır. Bu raporda, 40 yaşında immünkompetan kadın hastada gelişen ve başlangıcından 20 yıl sonra tanı alabilen Scedosporium apiospermum kompleks miçetoma enfeksiyonunun sunulması amaçlanmıştır.

\section{OLGU SUNUMU}

Bu çalışma, Sağlık Bilimleri Üniversitesi Şişli Hamidiye Etfal Eğitim ve Araştırma Hastanesi Sağlık Uygulama ve Araştırma Merkezi Klinik Araştırmalar Etik Kurulu onayı ile gerçekleştirildi (Tarih: 25 Ağustos 2020 ve Karar No: 2944). Hastadan onam formu alındı.

Kırk yaşında kadın hasta sağ el ve el bileği dorsalinde ağrı, şişlik ve birden fazla fistülize akıntılı yara şikayeti ile Ocak 2015 tarihinde ortopedi kliniğine başvurdu. Şikayetlerinin yaklaşık 20 yıl önce el bileği sırtında hafif bir şişlikle başladığı ve şişliğin artması üzerine özel bir cerrahi merkezde apsenin direne edilerek antibiyotik tedavisine başlandığı öğrenildi. Ancak tedavilerden fayda görmediği gibi zamanla el ve el bileği sırtında fistülize sarı akıntılı yaralar geliştiği ve çeşitli cerrahi müdahaleler geçirip tekrar antibiyotik kullandığı öğrenildi. Hasta sülük tedavisi de uygulattığını ancak fayda görmediğini belirtti. Hasta 11-12 yaşında el bileği üzerine düşme ve sınıkçı müdahalesi öyküsü olduğunu ancak açık yara olup olmadığını hatırlayamadığını belirtti. Hayvancılık öyküsü de bulunan hastanın altta yatan kronik bir hastalığı yoktu. Fizik muayenede, sağ el bileğinde pasif ve aktif eklem hareket açıklığı azalmış olup eklem hareketleri ağrılıydı. Nabızlar palpabl, motor ve duyu sinir muayenesi normaldi. C-reaktif protein (CRP), sedimentasyon, tam kan sayımı 
ve rutin biyokimyasal tetkikleri normal sınırlardaydı. El ve el bileği radyografik görüntülemede (RG); karpal kemiklerin formasyon ve diziliminin bozulduğu, yer yer lusens alanlar olduğu görüldü. Manyetik rezonans görüntülemede (MRG), tüm karpal kemiklerde ve 2, 3 ve 4. metakarp başlarında destruksiyon, deformasyon, kemik iliği ödemi ve yumuşak doku komponentlerinin de eşlik ettiği yoğun kontrast tutulumu olduğu görüldü (Şekil 1). MRG ve RG bulguları osteomyelitle uyumluydu ve $M R G$ 'de miçetoma için karakteristik olan "dot in circle (çember içinde nokta)" bulgusu görüldü (Şekil 1). Açık biyopsi ve debridman yapılan hastadan patolojik ve mikrobiyolojik inceleme için örnekler alındı. Hastaya siprofloksasin (750 mg, $2 \times 1$ ) ve rifampisin (300 mg, 1 × 2) tedavisi düzenlendi. Patolojik inceleme, yumuşak dokuda aktif kronik iltihabi reaksiyon ve kronik osteomyelit olarak yorumlandı.

Rutin bakteriyoloji kültüründe üreme olmadı. Örnekte aside dirençli basil görülmedi ve mikobakteri kültürlerinde üreme olmadı. Quantiferon testi negatifti. Mantar kültürünün 11. gününde $25^{\circ} \mathrm{C}^{\prime}$ de inkübe edilen Sabouraud dekstroz agar (SDA) besiyerinde ve eş zamanlı olarak $37^{\circ} \mathrm{C}^{\prime}$ de inkübe edilen koyun kanlı agar, çikolata agar ve SDA besiyerinde gelişen mantar miçellerinin görülmesi üzerine klinikle görüşülüp ikinci bir örneğin gönderilmesi önerildi. Patates dekstroz agarda $25^{\circ} \mathrm{C}^{\prime}$ de krem rengi başlayarak gri-kahverengiye dönen, pamuksu yapıda, arkası siyah görünümdeki mantarın laktofenol pamuk mavisi incelemesinde, farklılaşmamış septumlu hiflerden ortaya çıkan tekli, renksiz-açık kahverengi, tabanı kesik gibi görünen (trunkat) oval konidyumlar görüldü (Şekil 2). Morfolojik özelliklerinin incelenmesi sonucunda Scedosporium spp. olarak tanımlandı. Illk örnekten bir ay sonra gönderilen ikinci biyopsi örneğinde mikobakteri üremedi. İkinci kültürde de aynı morfolojide mantar üredi. İzolatlar; PDA besiyerinde sarı pigment oluşturmamasıyla S.aurantiacum'dan, arka görünümünün siyah olmasıyla S.dehoogii ve S.minutispora'dan, şişe benzeri konidyoforlarının olmamasıyla L.prolificans'dan morfolojik olarak ayrılmaktadır ${ }^{8}$. İzolatlar; matriks aracılı lazer desorpsiyon/iyonizasyon, uçuş zamanı kütle spektrometre (MALDI-TOF MS) sistemi, MALDI Biotyper (Bruker Daltonics, Bremen, Almanya) ve Filamentous Fungi Library v1.0 veri tabanı kullanılarak en yüksek 1.86 skorla Scedosporium apiospermum/Pseudallescheria boydii olarak tanımlandı. Moleküler yöntemle tanımlamada; ITS1-5.8S-ITS2 bölgesine özgü -"forward" primer (5'- TCC TCC GCT
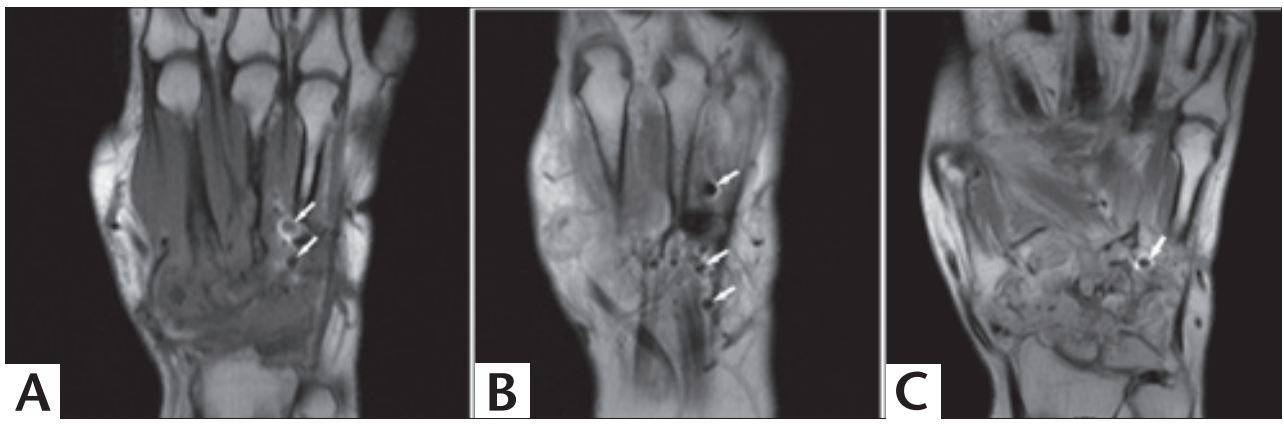

Şekil 1. Sağ el T1 ağırıkı MRG koronal kesitlerinde "dot in circle (çember içinde nokta)" bulgusu; A) Kontrastsız görüntüleme, B-C) Kontrastlı görüntüleme. 


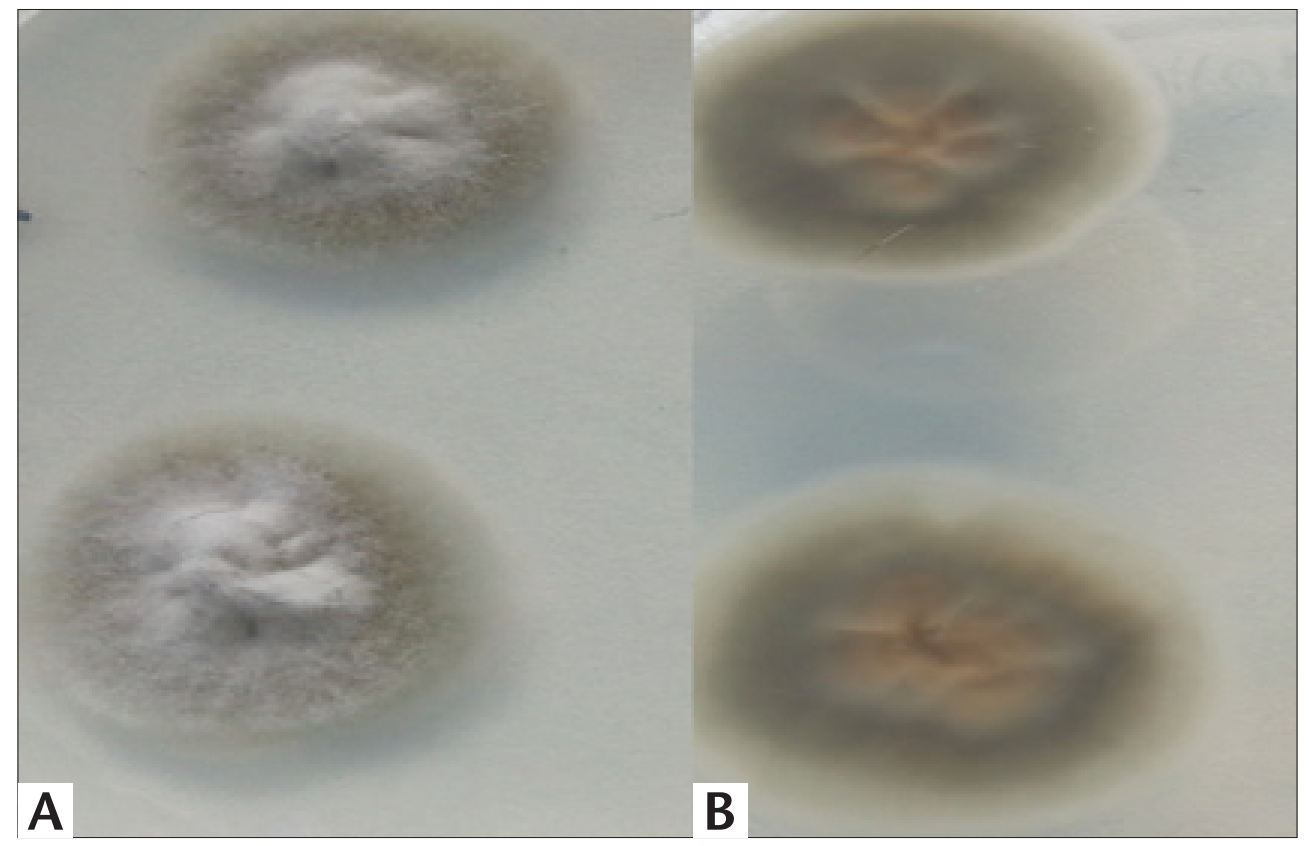

Şekil 2. Patates dekstroz agarda $25^{\circ} \mathrm{C}^{\prime}$ de üreyen önden gri-kahverengi pamuksu görünümde (A), arkadan siyah görünümde mantar kolonisi (B).

TAT TGA TAT GC-3') ve "revers primer" (5'- GGA AGT AAA AGT CGT AAC AAG G-3') çifti kullanılarak polimeraz zincir reaksiyonu (PCR) uygulandı ${ }^{9}$. Fungal amplikonların dizi analizi $A B I$ prism "Big dye terminator cycle sequencing ready reaction" kit kullanılarak "ABI Prism 377 DNA Sequencer (Applied Biosystems, ABD)" ile belirlendi ve Scedosporium boydii (\%99 benzerlikle KM461120.1 Gen Bank Accession number; \%99.8 benzerlikle CBS 116898_ITS, ISHAM Barcoding Database) olarak tanımlandı.

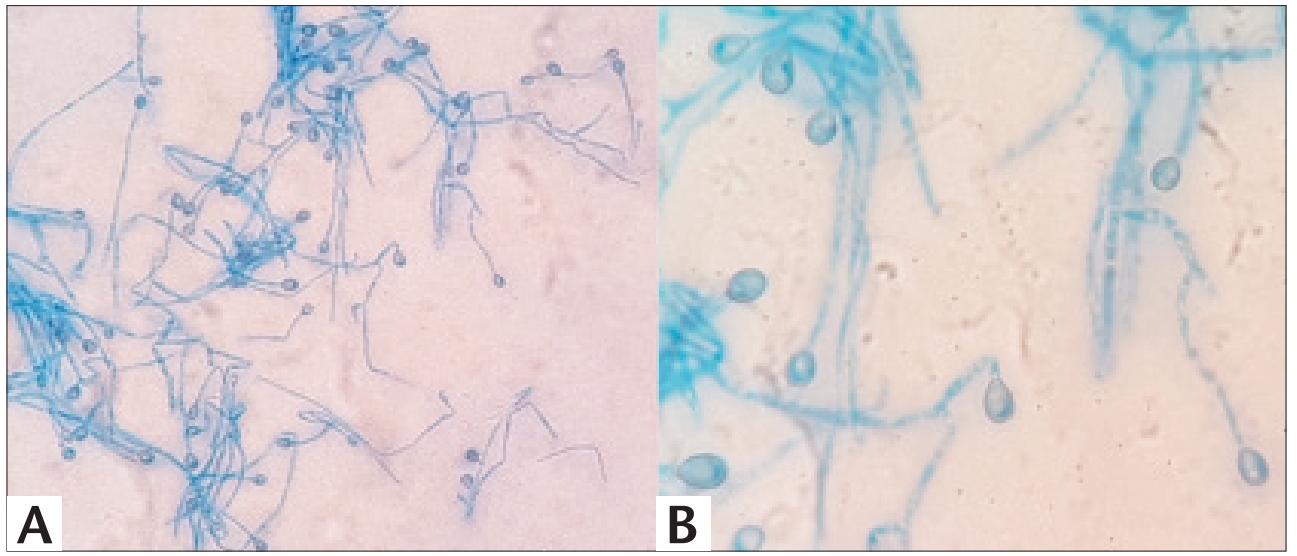

Şekil 3. Laktofenol pamuk mavisi ile mikroskobik görüntüsü; farklılaşmamış septumlu hiflerden ortaya çıkan tekli, renksiz-açık kahverengi, tabanı kesik gibi görünen (trunkat) oval konidyumlar: (A) 40x objektif, (B) 100x objektif. 
İzolatların antifungal duyarlılık testi sıvı mikrodilüsyon yöntemiyle "Clinical Laboratory Standards Institute (CLSI)" M38-A2 kriterlerine göre uyguland ${ }^{10}$. MiK değerleri 72. saat sonunda değerlendirilerek flukonazol için > $64 \mu \mathrm{g} / \mathrm{ml}$, kaspofungin için $16 \mu \mathrm{g} / \mathrm{ml}$, amfoterisin B için $4 \mu \mathrm{g} / \mathrm{ml}$, itrakonazol için $16 \mu \mathrm{g} / \mathrm{ml}$, vorikonazol için $0.25 \mu \mathrm{g} / \mathrm{ml}$, posakonazol için $2 \mu \mathrm{g} / \mathrm{ml}$ ve isavukonazol için $0.25 \mu \mathrm{g} / \mathrm{ml}$ olarak belirlendi. Hastaya vorikonazol (200 mg, $2 \times 1)$ ve terbinafin $(250$ mg, $1 \times 1)$ tedavisi başlandı ve 18 ay süreyle devam edildi. Tedavinin üçüncü ayında yapılan kontrollerinde bulanık görme şikayeti üzerine yapılan oftalmolojik muayenesinde patoloji saptanmadı ve altı aylık kontrollerle tedaviye devam edildi. Tedavinin dokuzuncu ayında yapılan kontrol muayenesinde fistül ağızlarının kapandığı, ağrı ve şişlik şikayetlerinin geçtiği, el bileği eklem hareket açıklığının tedavi öncesine göre bir miktar arttığı ve hareketlerin ağrısız olduğu görüldü. Tedavinin 15 ve 18. ayında yapılan kontrol MRG incelemesinde yumuşak doku tutulumu olmadığı, interkarpal eklemlerde lizis, deformasyon ve eklem mesafelerinde daralma olduğu, karpometakarpal eklem ilişkisinin kısmen korunduğu ve bulguların osteomyelit sonrası artrozik enflamatuvar değişiklikler olduğu belirtildi ve 18 aylık tedavi sonlandırıldı.

\section{TARTIŞMA}

Miçetoma yakın zamanda Dünya Sağlık Örgütü tarafından 'ihmal edilen tropikal bir hastalık' olarak kabul edilmiştir². Miçetoma, mantarla kontamine toprağa maruz kalmış diken, kıymık, tarım aletleri gibi yabancı cisimlerle oluşan travma sonrasında gelişmektedir. Osteoartiküler enfeksiyonlar ise travma dışında, intraartiküler steroid uygulanması ya da cerrahi bir işlem sonrasında gelişmektedir. Bazı vakalarda enfeksiyonun minör cilt travmaları ile oluşan abrazyonlardan kaynaklandığı bildirilmiştir ${ }^{5}$. Vücudun farklı bölgelerinde görülebilirken en sık ayak ve el etkilenmektedir ${ }^{1-3}$. Dokuda şişlik, sinüs oluşumu ve granül yapılarının görülmesi miçetoma enfeksiyonlarını akla getirmelidir ${ }^{5}$. Bu olguda çocukluk çağında geçirilen bir travma hikayesi mevcuttur. Hasta, geçmişinde akıntılı yarasında granül bulunduğunu tariflemiş ancak birçok cerrahi girişim geçirdiği için granüllü akıntının hangi dönemde geliştiği netleştirilememiştir. Mantar inokülasyonunun çocukluk dönemindeki travmadan ya da cerrahi bir işlem sonrasında gelişmiş olabileceği düşünülmüştür.

Miçetoma tanısı klinik deneyim ve çeşitli inceleme yöntemlerinin (laboratuvar, görüntüleme ve histopatoloji) kombinasyonuyla yapılmaktadır ${ }^{2}$. Tanıda altın standart olan kültür yöntemiyle etiyolojik ajanın elde edilmesi neticesinde hastaların uygun şekilde yönetilmesine yardımcı olunmaktadır ${ }^{1}$. Histopatolojik ve mikroskobik incelemede granüllerde filamentöz basiller (aktinomiçetoma) veya septalı hiflerin (miçetoma) görülmesi ve MRG incelemede miçetoma için karakteristik bir bulgu olan "dot in circle" bulgusunun görülmesi tanıda kullanılmaktadır². Nadir görülmesi ve özgül olmayan bulgular göstermesi nedeniyle miçetoma tanısı endemik olmayan yerlerde aylar hatta yıllarca gecikebilmektedir ${ }^{3}$. Olgumuzda yaklaşık 20 yıllık bir süreçte farklı merkezlerde defalarca cerrahi girişim ve antibiyotik kullanımı olmuştur. Ancak yeterli klinik deneyim olmaması ve/veya mikolojik kültürlerin her merkezde yapılamaması nedeniyle mantar tanısı atlan- 
mıştır. Gönderilen her iki örnekte de mantar üremesinin görünür boyuta gelmesi 10-12 gün sürmüştür. Bakteriyolojik kültürlerin inkübasyon süresi 3-5 gün olduğu için mantar üremesi için gereken süre yetersiz kalmaktadır. Bakteriyolojik kültürlerin üremesiz sonuçlandığı, antibiyoterapiye yanıtsız olgularda ayıııı tanıda mantar enfeksiyonları muhakkak akla getirilmelidir. Olgumuzda histopatolojik inceleme sonucunda mantar enfeksiyonu lehine bulgu belirtilmemiştir. Ancak farklı zamanlarda alınan iki derin biyopsi örneğinden aynı mantarın izole edilmesi, antifungal tedaviye cevap alınması ve MRG'de "dot in circle" bulgusunun görülmesi izolatın etken olduğunu desteklemektedir.

Miçetoma enfeksiyonlarının sık rastlanan etkenleri arasında Scedosporium cinsi yer almaktadır ${ }^{11,12}$. Morfolojik ve biyokimyasal reaksiyonlardaki davranış özellikleri S.apiospermum kompleks içindeki bazı türlerin ayrılmasında yetersiz kalmaktadır ${ }^{4}$. Mantarların tanımlanmasında rDNA "internal transcribed spacer (ITS)" dizi analizi yöntemi mevcut olan altın standart yöntemdir. Scedosporium cinsindeki bazı ana türlerin tanımlanmasını sağlayabilir. Ancak yakın ilişkili türlerin ayırt edilmesi için beta-tübülin geni gibi ek gen bölgelerinin değerlendirilmesi gereklidir ${ }^{5,13}$. İzolatların moleküler tanımlamasında sadece ITS gen bölgesinin dizi analizinin yapılması çalışmanın eksik yönü olarak belirlenmiş ve etken S.apiospermum kompleks olarak kabul edilmiştir. Mikrobiyoloji laboratuvarlarında kullanımı artan MALDI-TOF MS sistemleriyle bakteri ve mayalarda hızı ve güvenilir tanımlama yapılabilmektedir. Ancak filamentöz mantarların farklı fenotipik yapılar oluşturmaları, misel yapıları ve büyüme koşullarından etkilenebilmelerinden dolayı protein spektrumları değişmektedir. Ticari olarak temin edilen sistemlerin kullandığı referans spektrum kütüphanelerinin bazı mantarların tür ayrımında yetersiz kalabileceği belirtilmektedir. Çalışmalarda referans türlerin spektrumlarının kütüphaneye eklenmesiyle başarılı sonuçlar alınmaktadı ${ }^{14}$. Bu olgunun izolatları MALDI Biotyper sisteminde Scedosporium apiospermum/Pseudallescheria boydii olarak cins düzeyinde doğru tanımlanmış ancak tür düzeyinde tanımlanamamıştır. S.boydii MALDI Biotyper sisteminin veri tabanında bulunmamaktadır. Taksonomik gelişmelere paralel olarak veri tabanlarının sürekli güncellenmesiyle tanımlama başarısı artacaktır.

Scedosporium cinsinin neden olduğu enfeksiyonlarda en sık bildirilen etkenler sırasıyla S.apiospermum ve S.boydii'dir ${ }^{11,15}$. Çevresel örneklerdeki dağılımı ülkeden ülkeye değişmekle birlikte genellikle en sık S.apiospermum ardından S.dehoogii ve S.boydii izole edilmiştir ${ }^{6}$. Scedosporium miçetoma vakaları dünyada yaygın görülmektedir. Avrupa, Amerika Birleşik Devletleri ve Brezilya'da bildirilen Scedosporium miç̧etoma vakalarında etken S.apiospermum/S.boydii olarak bildirilmiştir. Ancak izolatların tanımlanmasında çoğunlukla klasik yöntemler kullanıldığı için kesin tür tanımı ve diğer Scedosporium türlerinin rolü tam olarak bilinmemektedir ${ }^{4}$. Ülkemizde ilk olarak 1967 yllında Ekmen ve arkadaşları tarafından ${ }^{16}$ miçetoma enfeksiyonundan izole edilmiş, ardından birçok vakada etken olarak bildirilmiştir ${ }^{17}$.

Miçetoma enfeksiyonlarında subkutan dokularda, zaman içerisinde bağlar, eklem kıkırdağı ve kemik etkilenerek uzuvlarda şekil bozukluğu ve işlev kayıpları görülmekte- 
dir $^{4}$. Çocuklarda ve yetişkinlerde gelişen 145 osteoartiküler enfeksiyon vakasının retrospektif olarak değerlendirildiği bir çalışmada; Aspergillus dışı küf mantarları arasında en sık Scedosporium cinsinin etken olduğu ${ }^{11}$, diğer bir çalışmada ise ikinci sırada yer aldığı belirtilmiştir $^{12}$. Scedosporium cinsinde mevcut tüm antifungal ilaçlara duyarlılığın sınırlı olması nedeniyle enfeksiyonların yönetimi zordur. S.aurantiacum antifungal ilaçlara duyarlılığı en az olan türdür. Literatür ve olgumuz verilerine göre Scedosporium türlerine en etkili antifungal vorikonazoldür ve enfeksiyonların tedavisinde ilk seçenek olarak yer almaktadır. Ayrıca mümkünse cerrahi debridman yapılması da önerilmektedir ${ }^{4,18}$. Antifungal direncin yüksek olması, türler arasında değişkenlik göstermesi ve tür tanımındaki zorluklar neticesinde tedavide antifungal kombinasyonlarının kullanımı faydalı olmaktadır $^{4,13}$. Scedosporium spp. ve L.prolificans mantarlarına karşı yapılan in vitro antifungal duyarlııı kombinasyon çalışmalarında vorikonazolün amfoterisin B, kaspofungin ve terbinafinle kombinasyonunda sinerjik etki gösterdiği belirlenmiştir ${ }^{4,12,19}$. Avrupa'da bir S.apiospermum miçetoma olgusunda cerrahi debridmanla birlikte terbinafin tedavisinin etkili olduğu bildirilmiştir ${ }^{18}$. Bu olguda cerrahi debridman ve 18 ay süresince vorikonazol ve terbinafin kombinasyon tedavisi uygulanmıştır. Tedavi sürecinde düzenli oftalmolojik muayene ile tedaviye ara vermeyi gerektirmeyen aralıkı bulanık görme yan etkileri gelişmiştir. Hastanın tedavi süresince radyolojik bulgularında gerileme ve klinik iyileşme görülmüştür.

Uzun süreli şikayetleri mikolojik tanı ve uygun tedavi ile düzelmiş olan bu olgu, kronik kemik ve yumuşak doku enfeksiyonlarında mikolojik tanının akla getirilmesinin önemini ortaya koymaktadır. Mantarın cins ve tür düzeyinde tanımlanması ve tedavinin antifungal duyarlık test sonuçlarına göre düzenlenmesi hasta yönetiminde oldukça önemlidir.

\section{ETIK KURUL ONAYI}

Bu çalışma, Sağlık Bilimleri Üniversitesi Şişli Hamidiye Etfal Eğitim ve Araştırma Hastanesi Sağlık Uygulama ve Araştırma Merkezi Klinik Araştırmalar Etik Kurulu onayı ile gerçekleştirildi (Tarih: 25 Ağustos 2020 ve Karar No: 2944). Hastadan onam formu alındı.

\section{ÇIKAR ÇATIŞMASI}

Yazarlar bu makale ile ilgili herhangi bir çıkar çatışması bildirmemişlerdir.

\section{KAYNAKLAR}

1. Emmanuel P, Dumre SP, John S, Karbwang J, Hirayama K. Mycetoma: a clinical dilemma in resource limited settings. Ann Clin Microbiol Antimicrob 2018; 17(1): 35.

2. Verma P, Jha A. Mycetoma: reviewing a neglected disease. Clin Exp Dermatol 2019; 44: 123-9.

3. Wang R, Yao X, Li R. Mycetoma in China: A Case Report and Review of the Literature. Mycopathologia 2019; 184(2): 327-34.

4. Ramirez-Garcia A, Pellon A, Rementeria A, Buldain I, Barreto-Bergter E, Rollin-Pinheiro R, et al. Scedosporium and Lomentospora: an updated overview of underrated opportunists. Med Mycol 2018; 56: 102-25.

5. Subedi S, Chen S.C. Epidemiology of Scedosporiosis. Curr Fungal Infect Rep 2015; 9: $275-84$. 
6. Rougeron A, Giraud S, Alastruey-Izquierdo A, Cano-Lira J, Rainer J, Mouhajir A et al. Ecology of Scedosporium Species: Present knowledge and future research. Mycopathologia 2018; 183(1): 185-200.

7. Slavin M, van Hal S, Sorrell TC, Lee A, Marriott DJ, Daveson K, et al. Invasive infections due to filamentous fungi other than Aspergillus: epidemiology and determinants of mortality. Clin Microbiol Infect 2015; 21(5): 490.

8. Ramsperger M, Duan S, Sorrell TC, Meyer W, Chen SC. The genus Scedosporium and Pseudallescheria: current challenges in laboratory diagnosis. Curr Clin Microbiol Rep 2014; 1(1-2): 27-36.

9. Schoch CL, Seifert KA, Huhndorf S, Robert V, Spouge JL, Levesque CA, et al. Nuclear ribosomal internal transcribed spacer (ITS) region as a universal DNA barcode marker for Fungi. Proc Natl Acad Sci USA 2012; 109(16): 6241-46.

10. Clinical and Laboratory Standards Institute : CLSI document M38-A2: reference method for broth dilution antifungal susceptibility testing of filamentous fungi; approved standard-Second Edition. Wayne: Clinical and Laboratory Standards Institute, 2008.

11. Taj-Aldeen SJ, Rammaert B, Gamaletsou M, Sipsas NV, Zeller V, Roilides E, et al. International osteoarticular mycoses consortium osteoarticular infections caused by non-Aspergillus filamentous fungi in adult and pediatric patients: a systematic review. Medicine (Baltimore) 2015 ;94(50): e2078.

12. Koehler $P$, Tacke $D$, Cornely OA. Bone and joint infections by Mucorales, Scedosporium, Fusarium and even rarer fungi. Crit Rev Microbiol 2016; 42(1): 158-71.

13. McCarthy MW, Katragkou A, losifidis E, Roilides E, Walsh TJ. Recent advances in the treatment of Scedosporiosis and Fusariosis. J Fungi (Basel) 2018; 4(2): 73.

14. Patel R. A Moldy Application of MALDI: MALDI-ToF Mass Spectrometry for Fungal Identification. J Fungi (Basel) 2019; 5(1): 4

15. Luplertlop N. Pseudallescheria/Scedosporium complex species: From saprobic to pathogenic fungus. I Mycol Med 2018; 28(2): 249-56.

16. Ekmen H, Erbakan N. Miçetoma Memleketimizde kültürel teşhisi yapılan 3 vak'a. Mikrobiyol Bul 1967; 1(3): 149-154.

17. Kantarcıoğlu, AS, Yücel A. Cerrahpaşa Tıp Fakültesi Mikrobiyoloji ve Klinik Mikrobiyoloji Anabilim Dalı'nda tanımlanmış olan Pseudallescheriasis olguları ve Avrupa Tıp Mikolojisi Konfederasyonu (ECMM) Pseudallescheriasis Çalışma Grubu. Cerrahpaşa Tıp Dergisi 2005; 36(2): 90-6.

18. Tóth EJ, Nagy GR, Homa M, Ábrók M, Kiss IÉ, Nagy G, et al. Recurrent Scedosporium apiospermum mycetoma successfully treated by surgical excision and terbinafine treatment: a case report and review of the literature. Ann Clin Microbiol Antimicrob 2017; 16(1): 31.

19. Cuenca-Estrella M, Alastruey-Izquierdo A, Alcazar-Fuoli L, Bernal-Martinez L, Gomez-Lopez A, Buitrago MJ, et al. In vitro activities of 35 double combinations of antifungal agents cagainst Scedosporium apiospermum and Scedosporium prolificans. Antimicrob Agents Chemother 2008; 52(3): 1136-9. 